\title{
IIMIII Prevalence of Intimate Partner Violence among Women Veterans who Utilize Veterans Health Administration Primary Care
}

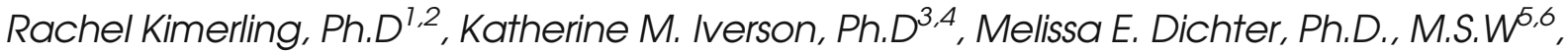
Allison L. Rodriguez, B.A. ', Ava Wong, M.P. $H^{2}$, and Joanne Pavao, M.P. $H^{7}$

'Department of Veterans Affairs, National Center for PTSD, VA Palo Alto Health Care System, Menlo Park, CA, USA; '2Department of Veterans Affairs, Center for Innovation to Implementation, VA Palo Alto Health Care System, Menlo Park, CA, USA; ${ }^{3}$ Department of Veterans Affairs, National Center for PTSD, VA Boston Healthcare System, Boston, MA, USA; ${ }^{4}$ Department of Psychiatry, Boston University School of Medicine, Boston, MA, USA ; ${ }^{5}$ Department of Veterans Affairs, Center for Health Equity Research and Promotion, Philadelphia VA Medical Center, Philadelphia, PA, USA;

${ }^{6}$ Department of Family Medicine and Community Health, Perelman School of Medicine, University of Pennsylvania, Philadelphia, PA, USA.

OBJECTIVES: The objectives of this study were to identify the prevalence of past-year intimate partner violence (IPV) among women Veterans utilizing Veterans Health Administration (VHA) primary care, and to document associated demographic, military, and primary care characteristics.

DESIGN: This was a retrospective cohort design, where participants completed a telephone survey in 2012 (84\% participation rate); responses were linked to VHA administrative data for utilization in the year prior to the survey. PARTICIPANTS: A national stratified random sample of 6,287 women Veteran VHA primary care users participated in the study.

MAIN MEASURES: Past-year IPV was assessed using the HARK screening tool. Self-report items and scales assessed demographic and military characteristics. Primary care characteristics were assessed via selfreport and VHA administrative data.

KEY RESULTS: The prevalence of past-year IPV among women Veterans was $18.5 \%$ ( $\mathrm{se}=0.5 \%$ ), with higher rates (22.2\% - 25.5\%) among women up to age 55. Other demographic correlates included indicators of economic hardship, lesbian or bisexual orientation, and being a parent/ guardian of a child less than 18 years old. Military correlates included service during Vietnam to post-Vietnam eras, less than 10 years of service, and experiences of Military Sexual Trauma (MST). Most (77.3\%, se = 1.2\%) women who experienced IPV identified a VHA provider as their usual provider. Compared with women who did not report past-year IPV, women who reported IPV had more primary care visits, yet experienced lower continuity of care across providers.

CONCLUSIONS: The high prevalence of past-year IPV among women beyond childbearing years, the majority of whom primarily rely on VHA as a source of health care, reinforces the importance of screening all women for IPV in VHA primary care settings. Key considerations for service implementation include sensitivity with respect to sexual orientation, race/ethnicity, and other aspects of diversity, as well as care coordination and linkages with social services and MST-related care.

KEY WORDS: domestic violence; women's health; veterans; primary care.

Received September 25, 2015

Revised March 1, 2016

Accepted March 31, 2016

Published online April 29, 2016
$\mathrm{J}$ Gen Intern Med 31(8):888-94

DOI: $10.1007 / \mathrm{s} 11606-016-3701-7$

(c) Society of General Internal Medicine 2016

\section{INTRODUCTION}

Intimate partner violence (IPV) is a major public health concern, with a broad range of negative mental, physical, and economic consequences for women. ${ }^{1-5}$ The US Preventive Services Task Force (USPSTF) recommends screening women of childbearing age for current IPV experiences, as early intervention can mitigate the health impact of IPV. ${ }^{6}$ These services are among the essential preventive services for women's health identified by the Institute of Medicine (IOM), ${ }^{7}$ and are covered by health plans without costsharing under the Affordable Care Act. ${ }^{8,9}$ Approximately $6.5 \%(362,014)$ of all Veteran VHA users today are women, and the size of this population is rapidly increasing with an influx of younger, reproductive-aged women recently returned from conflicts in Iraq and Afghanistan. ${ }^{10}$ The Veterans Health Administration (VHA), the nation's largest integrated health care system, is in the early stages of implementing a national IPV screening program, which includes screening, risk evaluation, safety planning, supportive services, and community linkages, integrated with a broad range of health care programs across the system. ${ }^{11}$

Identifying the prevalence of past-year IPV among this patient population can inform the development and evaluation of screening and intervention programs by helping providers better anticipate the scope of the problem and tailor IPV training programs in this context. Because VHA providers have identified a lack of knowledge regarding IPV prevalence and its correlates in the women Veteran population as barriers to implementation of IPV screening, ${ }^{12}$ information that speaks to these issues may encourage the adoption of IPV screening practice.

A recent systematic review estimates the past-year prevalence of IPV among women seeking primary care to be $19.9 \% ;^{13}$ no studies to date have investigated the national prevalence of recent IPV in VHA primary care settings. National health surveillance data indicate that women Veterans are at increased risk for IPV 
over the lifespan as compared to civilian women (33.0\% vs. $23.8 \%) .{ }^{14}$ Regional studies examining VHA users found even higher rates of IPV, with up to $28.8 \%$ of partnered women reporting past-year IPV in mail survey studies. ${ }^{15,16}$

Understanding patient-level factors that are associated with past-year IPV may help tailor programs to patients most at risk. The USPTF cites IPV risk factors such as younger age, substance abuse, and economic hardship. ${ }^{6}$ VHA serves as a safety net system to many users, and IPV risk factors such as economic hardship, homelessness or housing instability, or disability are over-represented among women using VHA services. ${ }^{17,18}$ Similarly, lesbian/bisexual women are at elevated risk for IPV, ${ }^{19}$ and are over-represented in the military. ${ }^{20}$ Little data can attest to whether military service confers a generalized risk for IPV exposure, or whether military experiences such as recent deployments, or military sexual trauma $(\mathrm{MST})^{21,22}$ confer specific risk for IPV following military service. In addition, there is little data to inform whether other aspects of military service, such as age at joining the military, branch or unit of service, or length of time served, act as either risk or protective factors with respect to IPV. Furthermore, as women Veteran patients are more likely to disclose IPV to a VHA provider in the context of an ongoing relationship with that provider, ${ }^{23}$ understanding variation in VHA primary care service receipt as a function of IPV can further inform screening and response programming. The current study utilizes a large nationally representative sample of women Veteran primary care users to: 1) determine the prevalence of past-year IPV; 2) identify demographic and military risk factors and correlates of IPV; and 3) explore primary care characteristics relevant to implementation of universal screening for IPV.

\section{METHODS}

This is a retrospective cohort study utilizing data from the WOMAN (Women's Overall Mental Health Assessment of Needs) survey, a telephone survey conducted with a national population-based, sample of 6287 women Veterans. Sampling was stratified by age and race/ethnicity, with an over-sample of non-white women and women below age 44. The sampling frame was drawn from medical records of women veterans with at least one VHA primary care visit within the 50 United States or the District of Columbia during fiscal year $2011 .^{24}$ Surveys were conducted by trained interviewers from July through September 2012 and 84\% percent of eligible women with verified contact information participated in the study. The survey was linked to past-year VA administrative data sources to characterize health care utilization. This study was approved by the Stanford University Institutional Review Board. Oral consent was obtained prior to telephone interviews, and a waiver of documentation was obtained to protect confidentiality.

Past-year IPV was assessed using the Humiliation, Afraid, Rape, Kick (HARK) screening instrument, which includes four dichotomous (yes/no) items that assess emotional/ psychological violence, fear of partner/ex-partner, sexual violence, and physical violence. ${ }^{25}$ For telephone administration, behaviorally specific prompts were added (partner or expartner: "This includes a date or someone you have dated"; emotional abuse: "By this we mean things like called names, criticized, not allowed to see family or friends, humiliated, or put on an allowance by a partner or ex-partner?"). The item for sexual violence was also modified to include threats of force in addition to forced sex. An affirmative response to any of the four items was scored as positive for past-year IPV. The HARK is recommended by the $\mathrm{USPSTF}^{6}$ and $\mathrm{IOM}^{26}$ for screening due to high levels of sensitivity and specificity for identification of IPV. Participants were first asked if they were in a "safe or private place" to respond to questions about "relationships with intimate partners," and for the $3.6 \%$ of women who indicated that they were not, the HARK was not administered.

Demographic and military characteristics were obtained from the survey except for rural residence, which was obtained from VA Planning Systems Support Group enrollment files. ${ }^{27}$ Demographic characteristics included sexual orientation ("Do you think of yourself as straight or heterosexual, as gay, lesbian, or homosexual, or as bisexual?"), housing ("In the past year, have you been without your own housing for any period of time? This can include living on the street, or in a car, or temporary shelter for any period of time, or temporarily staying with friends or family"), and use of public assistance ("Do you currently receive food stamps, Temporary Assistance for Needy Families (TANF), Supplemental Security Income (SSI), general assistance, government rent subsidies, Medicaid, or other public assistance not related to your Veteran status?"). Parent/guardian status was defined as having one or more children younger than 18 years of age in the household, and considering oneself a parent, step-parent, guardian, or primary care-giver for the child(ren). Combat exposure was assessed with four items from the Department of Defense Post-Deployment Health Assessment, ${ }^{28}$ assessing service in a combat or conflict zone that included any of the following exposures: exposure to dead or wounded; discharging a weapon; or feeling "in great danger of being hurt or killed." MST was assessed using the seven-item sexual harassment subscale of the Deployment Risk and Resilience Inventory, ${ }^{29}$ and was coded positively if a woman reported any of the following: repeated crude or offensive sexual remarks or rumors; coercive sexual activity as a result of rewards or special treatment, or as a result of threats of harm or retaliation; sexual assault; or rape.

Because $44 \%$ of women reported dual use of VA and nonVA health care, we included a variable for the usual source of primary care, coded as a usual provider in VA, non-VA, or no usual source of care, ${ }^{30}$ in response to the item "Do you have one person who you think of as your regular doctor or primary care doctor?" Past-year primary care visits ${ }^{10}$ were obtained from VA Medical SAS Outpatient Event files. Categories of low $(\leq 2)$, moderate $(3-5)$ and high $(6+)$ utilization were 
created using a tertile split of the total number of visits. Among women with moderate to high utilization, usual provider continuity, ${ }^{31}$ representing the proportion of primary care visits with same provider, was calculated as an indicator of continuity of care, and categorized as perfect (100\%), high (75-99\%), moderate $(50-74 \%)$, or poor $(<50 \%)$.

\section{Data Analyses}

Data were weighted in analysis to adjust for complex sampling and survey non-response, with post-stratification weighting to reflect the population of women Veteran primary care users. Logistic regressions were used to model age-adjusted odds of past-year IPV as a function of demographic and military characteristics. Multinomial logistic regression was used to model usual source of primary care, level of primary care utilization, and continuity of care as a function of IPV, adjusting for age group, race, and ethnicity, as well as clustering within VHA facilities. IPV non-response (3.6\%) was significantly associated with non-white race, low income, lack of housing in the past year, Navy service, and no MST experiences. Sensitivity analyses ${ }^{32}$ to assess the impact of IPV nonresponse were conducted using 1) assumptions of all missing values as positive, and then 2) all missing values as negative responses. Analyses were conducted in 2014 and 2015 using Stata SE version $12 .^{33}$

\section{RESULTS}

Overall, $18.5 \%(\mathrm{se}=0.51 \%)$ of women Veteran VHA primary care users reported experiencing IPV in the past year (sensitivity analyses: $21.7 \%(\mathrm{se}=0.54 \%)-17.8 \%(\mathrm{se}=0.49 \%)$. Figure 1 displays the prevalence of IPV, by violence type and age group, with the highest rates among women aged $18-30(25.5 \%$, se $=1.82 \%)$. Table 1 reports the age-adjusted prevalence of past-year IPV according to demographic characteristics. Women who were not employed full-time, received public assistance, had been homeless within the past year, or had an annual income of less than $\$ 25,000$ were more likely to have experienced IPV. Women who identified as lesbian or bisexual were also more likely to report IPV than heterosexual women. In addition, women who reported being married or cohabitating and those that were divorced/separated/widowed, were more likely to report IPV than women who had never been married, as were those who reported being a parent or guardian. Table 2 presents the prevalence of IPV according to military characteristics. Women who served during Vietnam to Post-Vietnam era, who had experienced MST, or who had served in the military for less than 10 years were more likely to report past-year IPV. Sensitivity analyses for positive nonresponse assumptions revealed associations of IPV with "other" race $(\mathrm{AOR}=1.3 ; 95 \% \mathrm{CI}=1.1-1.6)$, and significantly lower effect sizes for MST $(\mathrm{AOR}=1.9 ; 95 \% \mathrm{CI}=1.7-2.2)$; sensitivity analyses for negative nonresponse assumptions revealed significantly lower effect sizes for past-year lack of housing $(\mathrm{AOR}=2.6 ; 95 \% \mathrm{CI}=2.1-3.2)$ and low income $(\mathrm{AOR}=1.5 ; 95 \% \mathrm{CI}=1.3-1.7)$.

Table 3 shows primary care characteristics by IPV status. Reliance on a VHA provider as the usual source of care was more common among women who reported past-year IPV. Moderate to high levels of primary care utilization were also more common among women who reported IPV, as was poorer continuity of care.

\section{DISCUSSION}

This is the first study to examine the prevalence of past-year IPV among a nationally representative sample of women Veterans using VHA care. Nearly one in five women in VHA primary care have experienced IPV in the past year. Even higher rates of IPV were identified among younger women, as one in four women under the age of 30 reported IPV and similarly high rates of IPV were reported by women up to age 55. These prevalence rates provide VHA policy makers and providers with much-needed data on the scope

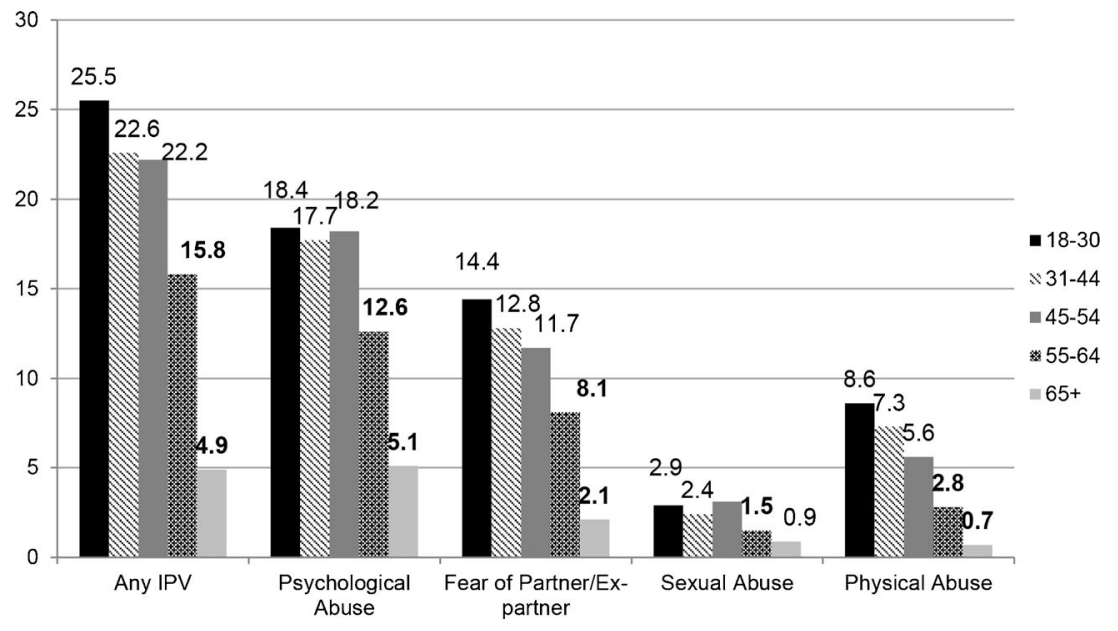

Figure 1. Prevalence of past-year IPV by age group among women VHA primary care users. Numbers in bold significantly differ from the preceding age group at $p<0.05$. 
Table 1. Prevalence of intimate partner violence by demographic characteristics of women veteran primary care users $(N=6046)$

\begin{tabular}{|c|c|c|c|c|c|}
\hline & \multirow[t]{2}{*}{ Total } & \multicolumn{2}{|l|}{ IPV } & \multirow[t]{2}{*}{$\mathrm{AOR}^{*}$} & \multirow[t]{2}{*}{$95 \% \mathrm{CI}$} \\
\hline & & $n$ & $\%(95 \% \mathrm{CI})$ & & \\
\hline \multicolumn{6}{|l|}{ Race } \\
\hline White & 4032 & 763 & $17.7(16.6-18.9)$ & 1.00 & - \\
\hline Black & 1364 & 240 & $18.8(16.7-21.1)$ & 0.89 & $0.75-1.05$ \\
\hline Other & 603 & 138 & $23.9(20.4-27.8)$ & 1.24 & $1.00-1.55$ \\
\hline \multicolumn{6}{|l|}{ Hispanic Ethnicity } \\
\hline Hispanic & 489 & 105 & $21.0(17.6-24.9)$ & 1.01 & $0.79-1.27$ \\
\hline Non-Hispanic & 5533 & 1039 & $18.3(17.3-19.4)$ & 1.00 & - \\
\hline \multicolumn{6}{|l|}{ Employment } \\
\hline Full time & 1745 & 270 & $15.2(13.6-17.1)$ & 1.00 & - \\
\hline Part time /self-employed & 730 & 149 & $20.5(17.7-23.8)$ & 1.66 & $1.32-2.10$ \\
\hline Out of work & 659 & 163 & $24.6(21.3-28.2)$ & 1.94 & $1.54-2.45$ \\
\hline Out of labor force & 2893 & 559 & $18.5(17.1-19.9)$ & 1.95 & $1.64-2.32$ \\
\hline \multicolumn{6}{|l|}{ Receiving Public Assistance } \\
\hline Yes & 1248 & 345 & $26.6(24.2-29.2)$ & 1.90 & $1.63-2.21$ \\
\hline No & 4771 & 800 & $16.3(15.3-17.4)$ & 1.00 & - \\
\hline \multicolumn{6}{|l|}{ Geographic Residence } \\
\hline Rural & 2383 & 471 & $19.0(17.5-20.7)$ & 1.13 & $0.98-1.30$ \\
\hline Urban & 3657 & 675 & $18.1(16.9-19.5)$ & 1.00 & - \\
\hline \multicolumn{6}{|l|}{ Without Housing in Past Year } \\
\hline Yes & 535 & 205 & $38.7(34.4-43.0)$ & 2.75 & $2.25-3.36$ \\
\hline No & 5503 & 942 & $16.5(15.6-17.6)$ & 1.00 & - \\
\hline \multicolumn{6}{|l|}{ Income } \\
\hline Less than $\$ 25,000$ & 2490 & 537 & $21.0(19.5-22.7)$ & 1.53 & $1.33-1.76$ \\
\hline More than $\$ 25,000$ & 3212 & 554 & $16.8(15.5-18.2)$ & 1.00 & - \\
\hline \multicolumn{6}{|l|}{ Sexual Orientation } \\
\hline Heterosexual & 5477 & 1021 & $18.0(17.0-19.1)$ & 1.00 & - \\
\hline Lesbian/Bisexual & 433 & 103 & $24.7(20.7-29.2)$ & 1.37 & $1.07-1.75$ \\
\hline \multicolumn{6}{|l|}{ Marital Status } \\
\hline Married/Cohabitating & 2656 & 480 & $17.6(16.1-19.1)$ & 1.28 & $1.03-1.58$ \\
\hline Divorced/Separated/Widowed & 2398 & 522 & $20.7(19.1-22.4)$ & 1.89 & $1.52-2.36$ \\
\hline & 972 & 145 & $15.5(13.2-18.1)$ & 1.00 & - \\
\hline \multicolumn{6}{|l|}{ Parent/Guardian } \\
\hline Yes & 1770 & 453 & $25.1(23.1-27.2)$ & 1.35 & $1.15-1.57$ \\
\hline No & 4273 & 693 & $15.7(14.7-16.9)$ & 1.00 & - \\
\hline
\end{tabular}

$I P V$, Intimate partner violence; AOR, Adjusted odds ratio; CI, Confidence interval

*AOR adjusts for age

Boldface indicates statistical significance $(p<0.05)$

of IPV exposure that can inform planning and guidelines for a national rollout of IPV screening programs. For example, it is noteworthy that VHA does not currently designate an upper age limit for screening, and the current findings suggest that VHA providers should consider screening all women for IPV, especially women under age 55 .

Findings revealed several important demographic and military characteristics that were associated with increased odds of reporting past-year IPV. Consistent with studies among both Veteran and civilian women, younger age was associated with the highest prevalence of IPV, ${ }^{17,22}$ though Vietnam-Era women may merit additional attention in understanding IPV among VHA's older women. Race and ethnicity were not associated with past-year IPV, as other Veteran studies have found. ${ }^{22,34}$ Studies of screening implementation should attend to race, however, as non-white race was associated with nonresponse to IPV items. Past-year IPV was associated with indicators of economic hardship, including lower levels of employment, receipt of public assistance, low income and past-year homelessness. Although we are not able to discern the temporal nature of these relationships, there is a substantial literature that suggests unemployment, ${ }^{35}$ reliance on public assistance, ${ }^{36}$ and homelessness ${ }^{37-39}$ to be consequences of
IPV. This set of findings suggests that policies to promote economic empowerment among women who experience IPV are relevant to meeting the needs of women Veterans. ${ }^{1}$ In addition, study findings point to the importance of coordination of a range of health and social services for women who experience IPV. Women Veterans who disclose IPV may benefit from referrals to other relevant VHA programs, such as homelessness and supported employment programs. Such post-disclosure interventions have significantly enhanced social service usage in non-VA settings. ${ }^{40}$

Elevated rates of IPV among women identifying as lesbian or bisexual are consistent with national surveillance data. ${ }^{19} \mathrm{It}$ is important to note that non-heterosexual sexual orientation does not necessarily indicate perpetration of IPV by a samesex partner, as bisexual and lesbian women may have experienced IPV from male partners. The important take-away for clinical care is to ensure that providers do not make assumptions about IPV experiences based on a patient's identified sexual orientation, or about heterosexual orientation in responding to IPV experiences. Outreach and response efforts, including materials, programs, and language used in clinical encounters, should be sensitive to diversity in gender identity and sexual orientation, as well as to (dis)ability, race, ethnicity, 
Table 2. Prevalence of intimate partner violence by military service characteristics of women veteran primary care users $(N=6046)$

\begin{tabular}{|c|c|c|c|c|c|}
\hline & \multirow[t]{2}{*}{ Total } & \multicolumn{2}{|l|}{ IPV } & \multirow[t]{2}{*}{$\mathbf{A O R}^{*}$} & \multirow[t]{2}{*}{$95 \% \mathrm{CI}$} \\
\hline & & $n$ & $\%(95 \% \mathrm{CI})$ & & \\
\hline \multicolumn{6}{|l|}{ Branch } \\
\hline Army & 3058 & 591 & $18.7(17.4-20.2)$ & 1.0 & - \\
\hline Navy & 1343 & 259 & $18.9(16.8-21.1)$ & 1.07 & $0.90-1.27$ \\
\hline Air Force & 1267 & 224 & $17.4(15.4-19.7)$ & 0.96 & $0.80-1.15$ \\
\hline Marines & 376 & 74 & $18.7(15.1-23.1$ & 1.05 & $0.79-1.39$ \\
\hline \multicolumn{6}{|l|}{ Unit } \\
\hline Active Duty & 5138 & 978 & $18.5(17.4-19.6)$ & 1.0 & - \\
\hline National Guard/Reserve & 880 & 169 & $19.2(16.6-22.1)$ & 0.94 & $0.78-1.15$ \\
\hline \multicolumn{6}{|l|}{ Period of Service } \\
\hline Pre-Vietnam & 364 & 21 & $4.0(2.5-6.6)$ & 0.62 & $0.32-1.19$ \\
\hline Vietnam to Post Vietnam & 2190 & 377 & $17.4(15.8-19.1)$ & 1.35 & $1.07-1.71$ \\
\hline Persian Gulf before $9 / 30 / 01$ & 1590 & 325 & $20.2(18.3-22.4)$ & 1.07 & $0.88-1.29$ \\
\hline Gulf War after $9 / 30 / 01$ & 1881 & 421 & $22.1(20.3-24.1)$ & 1.0 & - \\
\hline \multicolumn{6}{|c|}{ OEF/OIF Deployment among those serving after $9 / 30 / 01$} \\
\hline Yes & 1245 & 277 & $22.0(19.7-24.5)$ & 0.96 & $0.75-1.23$ \\
\hline No & 630 & 138 & $21.6(18.5-25.1)$ & 1.0 & - \\
\hline \multicolumn{6}{|l|}{ Combat Exposure } \\
\hline Yes & 1283 & 295 & $22.5(20.2-24.9)$ & 1.11 & $0.94-1.31$ \\
\hline No & 4750 & 851 & $17.4(16.4-18.6)$ & 1.0 & - \\
\hline \multicolumn{6}{|l|}{ Military Sexual Trauma } \\
\hline Yes & 3134 & 742 & $25.8(24.1-27.5)$ & 2.27 & $1.97-2.62$ \\
\hline No & 2856 & 396 & $12.2(11.1-13.4)$ & 1.0 & - \\
\hline \multicolumn{6}{|l|}{ Age Entered Military } \\
\hline$\leq 18$ & 2204 & 425 & $19.3(17.7-21.1)$ & 1.0 & - \\
\hline$\overline{19}-25$ & 2970 & 560 & $17.9(16.6-19.4)$ & 1.00 & $0.86-1.16$ \\
\hline $25+$ & 821 & 157 & $18.8(16.2-21.8)$ & 1.14 & $0.91-1.42$ \\
\hline \multicolumn{6}{|l|}{ Years of Military Service } \\
\hline$<2$ & 514 & 107 & $18.5(15.4-22.1)$ & 1.83 & $1.38-2.42$ \\
\hline $2-4$ & 2263 & 443 & $18.9(17.3-20.6)$ & 1.58 & $1.29-1.92$ \\
\hline $5-10$ & 1815 & 383 & $21.2(19.3-23.2)$ & 1.39 & $1.14-1.71$ \\
\hline $10+$ & 1440 & 213 & $14.7(12.9-16.7)$ & 1.0 & - \\
\hline
\end{tabular}

IPV, Intimate partner violence; AOR, Adjusted odds ratio; CI, Confidence interval; OEF/OIF, Operation Enduring Freedom/Operation Iraqi Freedom *AOR adjusts for age.

Boldface indicates statistical significance $(p<0.05)$

religion, and other characteristics as IPV affects individuals from all communities.

Elucidations of military risk factors for recent IPV also pose implications for VHA programs. That fewer years of military service was associated with past-year IPV experience is

Table 3. Association of intimate partner violence with primary care characteristics $(N=6046)$

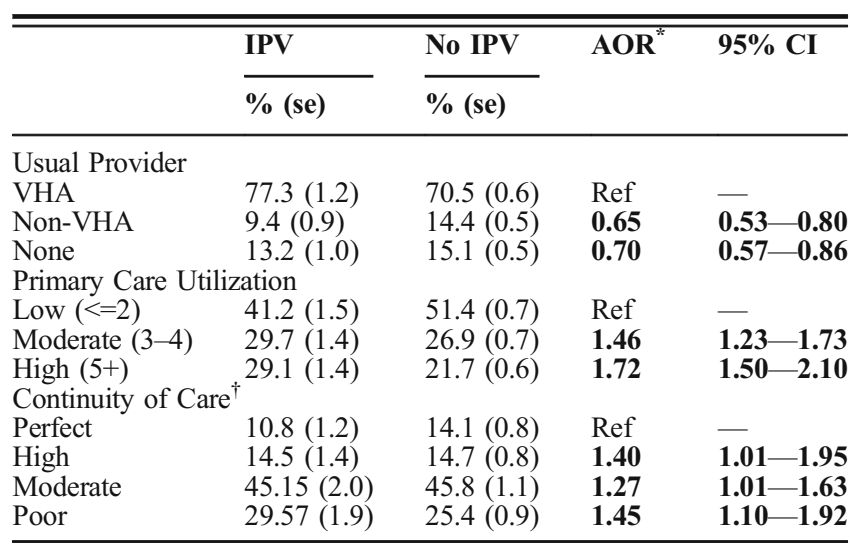

AOR, Adjusted odds ratio; CI, Confidence interval; IPV, Intimate partner violence; se, Standard error; VHA, Veterans Health Administration ${ }^{*}$ AOR adjusts for age, race, ethnicity, and clustering by VHA facility ${ }^{\dagger}$ Continuity of Care is calculated for women with moderate and high primary care utilization $(N=3021)$

Boldface indicates statistical significance $(p<0.05)$ consistent with research finding that gender-based interpersonal violence leads to premature separation from military service $^{41}$ and prior interpersonal violence poses significant risk for revictimization. ${ }^{42-45}$ Thus, women may have prematurely separated from military service due to violence and then also be at risk for future violence. This study replicated findings from smaller samples of women Veteran VHA patients ${ }^{22,34}$ indicating that women who experienced MST were more than twice as likely to report past-year IPV relative to women who did not have a MST history. As such, MST prevention and response programs may be particularly fruitful points of intervention for more generalized violence prevention. In VHA, there may be benefits to cross collaboration between MST coordinators and IPV coordinators, who serve as points of contact for programs with overlapping populations of Veterans.

Analysis of the health care context of women Veterans who experience IPV may be especially helpful in continuing to shape screening and counseling programs across the system. Women who reported past-year IPV were more likely to rely on VHA as their usual source of primary care. These findings emphasize the importance of detecting and responding to IPV within the VHA system. Consistent with non-VA data demonstrating elevated health care utilization and costs associated with recent IPV,${ }^{46,47}$ past-year IPV was associated with higher 
primary care utilization. However, women with past-year IPV were over-represented among women with lower continuity of care. Such fragmented care may limit opportunities to develop a trusting and connected relationship that would facilitate disclosure. $^{23,48}$ Thus, a focus on enhanced continuity of primary care may be a particularly relevant systems-level factor to promote effective screening programs in VHA. In addition, more research regarding VHA specialty care settings where women who have experienced recent IPV are likely to seek care, such as mental health services, ${ }^{49}$ may also yield important insights into opportunities for care coordination as well as opportunities to facilitate disclosure.

These results should be interpreted with several caveats. Data were collected via telephone survey, and IPV nonresponse associated with privacy or safety concerns resulted in a small degree of uncertainty around prevalence estimates. Additionally, despite the use of a sensitive and specific screen, ${ }^{25}$ recall bias could have impacted IPV prevalence estimates. Most importantly, screening measures are not a substitute for a comprehensive assessment of violence history and current safety afforded by a clinical encounter. Our study was focused on VHA primary care users in an effort to inform VHA programs. Results may not be generalizable to women Veterans treated in other health care settings, though rates of IPV $^{13}$ and primary care utilization $^{50,51}$ appear commensurate with other health care settings. Demographic correlates, such as sexual orientation and economic hardship, also replicate findings from other health care studies, and several implications of our results may be relevant for implementation of IPV screening outside VHA.

VHA has an opportunity to improve the health of women Veterans by implementing a comprehensive response to IPV. That nearly $20 \%$ of women Veteran VHA patients experience IPV within the past year underscores the importance of provider comfort with detection, sensitive response to disclosure, and effective, patient-centered intervention ${ }^{23}$ as a fundamental aspect of women Veterans health care. The higher primary care utilization among women who experienced IPV suggests there is ample opportunity. The elucidation of demographic and military characteristics associated with IPV in VHA provides the basis for tailoring detection and intervention efforts for women VHA users. Alongside community partners, VHA is developing training materials and processes of care to guide and support providers in implementing patient-centered IPV screening and response procedures. Although the implementation of these services is in its early stages, ongoing research will continue to inform VHA IPV programs.

\section{Acknowledgements:}

Contributors: The authors wish to thank Julie Karpenko MSW, Liberty Greene, MS, M.Ed and Meghan Saweikis, MS, JD, for their contributions to the WOMAN Study.

Corresponding Author: Rachel Kimerling, Ph.D; Department of Veterans Affairs, Center for Innovation to ImplementationVA Palo Alto
Health Care System, Menlo Park, CA, USA (e-mail: Rachel.Kimerling@va.gov).

Compliance with Ethical Standards:

Funding: This study was funded by the National Center for PTSD and VA HSR\&D SDR 12-196. The contributions of Drs. Dichter and Iverson to this manuscript were supported by VA HSR\&D CDA10-202 (MD) and CDA 10-029 (KI).

Disclaimer: The views expressed in this article are those of the authors and do not necessarily represent the position and policy of the Department of Veterans Affairs or the United States Government.

Conflict of Interest: The authors declare that they do not have conflicts of interest.

Financial Disclosure: All authors report no financial disclosures.

\section{REFERENCES}

1. Hahn SA, Postmus JL. Economic empowerment of impoverished IPV survivors: a review of best practice literature and implications for policy. Trauma Violence Abuse. 2014;15(2):79-93.

2. Spivak HR, Jenkins L, VanAudenhove $\mathbf{K}$, et al. CDC Grand Rounds: a public health approach to prevention of intimate partner violence. Morb Mortal Wkly Rep. 2014;63(2):38-41.

3. Wong J, Mellor D. Intimate partner violence and women's health and wellbeing: impacts, risk factors and responses. Contemp Nurse. 2014;46(2): 170-9.

4. Dillon G, Hussain R, Loxton D, Rahman S. Mental and physical health and intimate partner violence against women: a review of the literature. Int J Fam Med. 2013;2013:313909.

5. World Health Organization. Understanding and addressing violence against women: Intimate partner violence. Geneva, Switzerland: World Health Organization; 2012.

6. Moyer VA, U. S. Preventive Services Task Force. Screening for intimate partner violence and abuse of elderly and vulnerable adults: U.S. preventive services task force recommendation statement. Ann Intern Med. 2013;158(6):478-86.

7. Institute of Medicine. Clinical Preventive Services for Women: Closing the Gaps. Washington: DC; 2011.

8. Patient Protection and Affordable Care Act 119; 2010

9. de Boinville M. Screening for domestic violence in health care settings. Washington, DC: U.S. Department of Health and Human Services; 2013.

10. Frayne SM, Phibbs CS, Saecho F, et al. Sociodemographics, Utilization, Costs of Care, and Health Profile. Washington, DC: Department of Veterans Affairs, Women's Health Evaluation Initiative; 2014.

11. Veterans Health Administration Domestic Violence Task Force. Plan for Implementation of the Domestic Violence/Intimate Partner Violence Assistance Program. Department of Veterans Affairs, Veterans Health Administration;2013.

12. Iverson KM, Wells SY, Wiltsey-Stirman S, Vaughn R, Gerber MR. VHA primary care providers' perspectives on screening female veterans for intimate partner violence: a preliminary assessment. J Family Violence. 2013;28(8):823-31.

13. Sprague S, Goslings JC, Hogentoren C, et al. Prevalence of intimate partner violence across medical and surgical health care settings: a systematic review. Violence Against Women. 2014;20(1):118-36.

14. Dichter ME, Cerulli C, Bossarte RM. Intimate partner violence victimization among women veterans and associated heart health risks. Womens Health Issues. 2011;21(4 Suppl):S190-4.

15. Iverson KM, King MW, Resick PA, Gerber MR, Kimerling R, Vogt D. Clinical utility of an intimate partner violence screening tool for female VHA patients. J Gen Intern Med. 2013;28(10):1288-93.

16. Iverson KM, King MW, Gerber MR, et al. Accuracy of an intimate partner violence screening tool for female VHA patients: a replication and extension. J Trauma Stress. 2015;28(1):79-82.

17. Breiding MJ, Chen J, Black MC. Intimate Partner Violence in the United States-2010. Atlanta, GA: National Center for Injury Prevention and Control, Centers for Disease Control and Prevention; 2014.

18. Hahn JW, McCormick MC, Silverman JG, Robinson EB, Koenen KC. Examining the impact of disability status on intimate partner violence victimization in a population sample. J Interpers Viol. 2014;29(17):3063-85.

19. Walters ML, Chen J, Breiding MJ. The National Intimate Partner and Sexual Violence Survey (NISVS): 2010 Findings on Victimization by Sexual 
Orientation. Atlanta, GA: National Center for Injury Prevention and Control, Centers for Disease Control and Prevention; 2013.

20. Gates G. Lesbian, gay, and bisexual men and women in the US military: Updated estimates. The Williams Institute; 2010.

21. Fraser C. Family issues associated with military deployment, family violence, and military sexual trauma. NursClin N Am. 2011;46(4):445455, vi

22. Iverson KM, Mercado R, Carpenter SL, Street AE. Intimate partner violence among women veterans: previous interpersonal violence as a risk factor. J Trauma Stress. 2013;26(6):767-71.

23. Iverson KM, Huang K, Wells SY, Wright JD, Gerber MR, WiltseyStirman S. Women veterans' preferences for intimate partner violence screening and response procedures within the Veterans Health Administration. Res Nurs Health. 2014;37(4):302-11.

24. Kimerling R, Pavao JR, Greene $\mathbf{L}$, et al. Access to mental health care among women veterans: is VA meeting women's needs? Med Care. 2015;53(4 Suppl 1):S97-104

25. Sohal H, Eldridge S, Feder G. The sensitivity and specificity of four questions (HARK) to identify intimate partner violence: a diagnostic accuracy study in general practice. BMC Fam Pract. 2007;8:49.

26. Institute of Medicine. Capturing social and behavioral domains and measures in electronic health records: phase 2. Washington, DC: The National Academies Press; 2014.

27. Phibbs CS, Cowgill EH, Fan AY. Guide to the PSSG Enrollee File. Guidebook. Menlo Park, CA: VA Palo Alto, Health Economics Resource Center; 2013.

28. Department of Defense. Enhanced Post-Deployment Health Assessment (PDHA) Process (DD Form 2796); 2008.

29. King DW, King LA, Vogt DS. Manual for the Deployment Risk and Resilience Inventory (DRRI): A Collection of Measures for Studying Deployment-Related Experienced of Military Veterans. Boston, MA: National Center for PTSD; 2003.

30. Centers for Disease Control and Prevention. Behavioral Risk Factor Surveillance System. 2010; http://www.cdc.gov/brfss/questionnaires/english.htm.

31. Rodriguez HP, Marshall RE, Rogers WH, Safran DG. Primary care physician visit continuity: a comparison of patient-reported and administratively derived measures. J Gen Intern Med. 2008;23(9): 1499-502.

32. Sterne JAC, White IR, Carlin JB, et al. Multiple imputation for missing data in epidemiological and clinical research: potential and pitfalls. Br Med J. 2009;338:b2393.

33. Stata Statistical Software: Release 12 [computer program]. College Station, TX: StataCorp LP; 2011.

34. Dichter ME, Marcus SC. Intimate partner violence victimization among women veterans: health, health care service use, and opportunities for intervention. Mil Behav Health. 2013;1(2):107-13.

35. Kimerling R, Alvarez J, Pavao J, Mack KP, Smith MW, Baumrind N. Unemployment among women: Examining the relationship of physical and psychological intimate partner violence and posttraumatic stress disorder. J Interpers Violence. 2009;24(3):450-63.
36. Tolman RM, Raphael J. A review of research on welfare and domestic violence. J Soc Iss Spec Iss Impact Welfare Reform. 2000;56(4):655-82.

37. Baker CK, Billhardt KA, Warren J, Rollins C, Glass NE. Domestic violence, housing instability, and homelessness: a review of housing policies and program practices for meeting the needs of survivors. Aggress Violent Behav. 2010;15(6):430-9.

38. Hamilton AB, Poza I, Washington DL. "Homelessness and trauma go hand-in-hand": pathways to homelessness among women veterans. Womens Health Iss. 2011;21(4 Suppl):S203-9.

39. Pavao J, Alvarez J, Baumrind $\mathbf{N}$, Induni M, Kimerling R. Intimate partner violence and housing instability. Am J Prev Med. 2007;32(2):143-6.

40. Bair-Merritt MH, Lewis-O'Connor A, Goel S, et al. Primary care-based interventions for intimate partner violence: a systematic review. Am J Prev Med. 2014;46(2):188-94.

41. Dichter ME, True G. "This is the Story of Why My Military Career Ended Before it Should Have": Premature Separation from Military Service Among U.S. Women Veterans. Affilia; 2014.

42. Arata CM. From child victim to adult victim: A model for predicting sexual revictimization. Child Maltreat. 2000;5(1):28-38.

43. Desai S, Arias I, Thompson MP, Basile KC. Childhood victimization and subsequent adult revictimization assessed in a nationally representative sample of women and men. Violence Vict. 2002;17(6):639-53.

44. Noll JG, Horowitz LA, Bonanno GA, Trickett PK, Putnam FW. Revictimization and self-harm in females who experienced childhood sexual abuse: results from a prospective study. J Interpers Viol. 2003;18(12):1452-71.

45. Kimerling R, Alvarez J, Pavao J, Kaminski A, Baumrind N. Epidemiology and consequences of women's revictimization. Women's Health Iss. 2007; 17(2):101-6.

46. Bonomi AE, Anderson ML, Rivara FP, Thompson RS. Health care utilization and costs associated with physical and nonphysical-only intimate partner violence. Health Serv Res. 2009;44(3):1052-67.

47. Ford-Gilboe $\mathbf{M}$, Varcoe $\mathbf{C}$, Noh $\mathbf{M}$, et al. Patterns and predictors of service use among women who have separated from an abusive partner. J Fam Violence. 2015;30(4):419-31.

48. Katz DA, McCoy K, Sarrazin MV. Does improved continuity of primary care affect clinician-patient communication in VA? J Gen Intern Med. 2014;29(Suppl 2):S682-8.

49. Iverson KM, Vogt D, Dichter ME, et al. Intimate partner violence and current mental health needs among female veterans. J Am Board Fam Med. 2015;28(6):772-6.

50. Bertakis KD, Azari R, Helms LJ, Callahan EJ, Robbins JA. Gender differences in the utilization of health care services. J Fam Pract. 2000;49(2):147-52.

51. Rosenthal MB, Alidina S, Friedberg MW, et al. A Difference-in-Difference Analysis of Changes in Quality, utilization and cost following the Colorado multi-payer patient-centered medical home pilot. J Gen Intern Med. 2016;31(3):289-96. 